\title{
BMJ Global Health Establishment of a road traffic trauma registry for northern Sri Lanka
}

\author{
Thayasivam Gobyshanger, ${ }^{1}$ Alison M Bales, ${ }^{2}$ Claire Hardman, ${ }^{3}$ Mary McCarthy (iD ${ }^{2}$
}

\begin{abstract}
To cite: Gobyshanger T, Bales AM, Hardman C, et al. Establishment of a road traffic trauma registry for northern Sri Lanka. BMJ Global Health 2020;5:e001818. doi:10.1136/ bmjgh-2019-001818
\end{abstract}

Handling editor Seye Abimbola

This information was presented at the International Injury Care Committee (I2C2), American College of Surgeons Committee on Trauma meeting, San Antonio, Texas, 7 March 2018.

Received 3 July 2019

Revised 19 November 2019

Accepted 22 November 2019

Check for updates

C Author(s) (or their employer(s)) 2020. Re-use permitted under CC BY-NC. No commercial re-use. See rights and permissions. Published by BMJ.

${ }^{1}$ Orthopedic, Jaffna Teaching Hospital, Jaffna, Sri Lanka

${ }^{2}$ Surgery, Wright State University Boonshoft School of Medicine, Dayton, Ohio, USA

${ }^{3}$ Department of Surgery, Wright State Physicians, Dayton, Ohio, USA

\section{Correspondence to} Dr Mary McCarthy; mcmccarthy@premierhealth. com

\section{ABSTRACT}

Road traffic injuries are a neglected global public health problem. Over 1.25 million people are killed each year, and middle-income countries, which are motorising rapidly, are the hardest hit. Sri Lanka is dealing with an injury-related healthcare crisis, with a recent $85 \%$ increase in road traffic fatality rates. Road traffic crashes now account for 25 000 injuries annually and 10 deaths daily. Development of a trauma registry is the foundation for injury control, care and prevention. Five northern Sri Lankan provinces collaborated with Jaffna Teaching Hospital to develop a local electronic registry. The Centre for Clinical Excellence and Research was established to provide organisational leadership, hardware and software were purchased, and data collectors trained. Initial data collection was modified after implementation challenges were resolved. Between 1 June 2017 and 30 September 2017, 1708 injured patients were entered into the registry. Among these patients, $62 \%$ were male, $76 \%$ were aged $21-50$, $71.3 \%$ were motorcyclists and $34 \%$ were in a collision with another motorcyclist. There were frequent collisions with uncontrolled livestock (12\%) and with fixed objects (14\%), and most patients were transported by private vehicles without prehospital care. Head $(n=315)$ and lower extremity $(n=497)$ injuries predominated. Establishment of a trauma registry in low-income and middle-income countries is a significant challenge and requires invested local leadership; the most challenging issue is ongoing funding. However, this pilot registry provides a valuable foundation, identifying unique injury mechanisms, establishing priorities for prevention and patient care, and introducing the concept of an organised system to this region.

\section{INTRODUCTION}

Every year more than 50 million people sustain road traffic injuries requiring medical care $^{1}$ and 1.25 million die from their injuries. ${ }^{2}$ Those who survive are often left with disabilities that impact their quality of life and productivity. While fatality rates are falling in high-income countries (HICs), middleincome countries, with increased vehicle ownership, new paved roads and increased speeds, are the hardest hit. ${ }^{3}$ The United Nations General Assembly declared a Decade of Action for Road Safety from 2011 to $2020^{4}$ to combat these deadly trends. In 2015,

\section{Summary box}

Establishment of a trauma registry is the first step to understanding the regional epidemiology of injury and establishing an effective trauma system.

- Road traffic crashes result in $30 \%-86 \%$ of all trauma admissions in low-income and middle-income countries.

- Almost half of all motor vehicle collision victims were the main providers for their family.

- Data from the Sri Lankan Trauma Registry demonstrated that only $52 \%$ of patients arrived at the hospital within 2 hours after injury, with very few of these patients receiving any prehospital care.

- Work overload of medical officers led to a significant amount of missing data, and the slow tablet speed and poor internet connectivity within the wards led to a 30 min data entry time for a single patient.

- From the data obtained in this study, plans have been developed to conduct trauma first aid workshops and training programmes for school children and sports clubs, as well as public and media awareness programmes, of the importance of injury prevention in Sri Lanka.

road traffic injury was the cause of death in $1.07 \%$ of deaths occurring in HICs and nearly double $(2.03 \%)$ in low-income and middleincome countries (LMICs). ${ }^{2}$ An estimate of 1.8 million people could be saved through improvements in trauma care. ${ }^{5}$

Establishment of a trauma registry is the first step to understanding the regional epidemiology of injury. Ideally, the registry should be population-based, including all injuries and deaths. Compilation of data on prehospital, inpatient care and rehabilitation provides a comprehensive understanding. However, in LMICs, a hospital admission database with patient follow-up can provide a starting point for establishment of a trauma system.

The value of a trauma registry is performance improvement-benchmarking, assessing trauma system functioning, improving patient outcomes throughout the continuum of care and developing injury prevention strategies. Research from HICs has shown repeatedly that implementation 
and effective use of a trauma registry can improve patient outcomes. ${ }^{67}$ Critical patients are six times more likely to die from injuries in a country without an organised trauma system. ${ }^{8}$ Recent attempts to extrapolate this model to improve trauma patient outcomes in LMICs have been encouraging, ${ }^{9}$ leading the WHO to publish guidelines for trauma systems. ${ }^{10}$

Sri Lanka is dealing with an injury-related crisis, with a recent $85 \%$ increase in road traffic fatality rates. ${ }^{3}$ Crashes account for 25000 injuries yearly and 10 deaths every day. ${ }^{1}$ Trauma is the leading cause of hospitalisation in Sri Lanka, with a rate of 3100 admissions per 100000 population. ${ }^{1}$ Current expenditures are estimated to be in the range of 14.2 billion rupees ( $\$ 80$ million), with $37 \%$ of that cost dedicated to inpatient care. ${ }^{211}$ This study describes the implementation and findings of a trauma registry in northern Sri Lanka.

\section{ESTABLISHING THE TRAUMA REGISTRY}

The Centre for Clinical Excellence and Research (CeCER) was formed to provide trauma system organisational leadership. The primary author (TG) met with the Ministry of Health and province and hospital administrators, who granted permission for registry implementation. Workshops were held for healthcare providers and data collectors; data collection began in June 2017. A phased approach was used-introducing staff education and training, hardware and software design and modification, stakeholder participation, data collection and analysis, and finally release of results to institutions, provincial and central authorities with recommendations for trauma system development. Five districts in northern Sri Lanka were selected as study sites: Jaffna, Kilinochchi, Mullaittivu, Mannar and Vavuniya. Seven hospitals participated; three referred complex trauma patients to the 1228-bed Jaffna Teaching Hospital.

The data elements were abstracted from hospital records and definitions determined by a modified Delphi technique by the coordinating committee of CeCER. Tablet-based software was developed, collecting data from the scene through hospital discharge. Data elements included age, sex, ethnicity, educational status, occupation, time of crash, site of crash, mode of travel, collision elements, place of injury, road surface, light/visibility, dress, speed, alcohol consumption, history of crashes, hospital admission and treatment data, mode of transport and time to reach the hospital, first aid, transfer to higher level of care, indication for transfer, information passed on to police and judicial medical officers, injury pattern, duration of hospital stay, imaging performed, role of patient in the family economy, additional family cost, family income, home environment after trauma if disabled temporarily or permanently, job status after injury, and economic support during the injury. Limited data were available for recovery and rehabilitation. Data were collated, forwarded to the stakeholders and presented at local, regional and international forums.

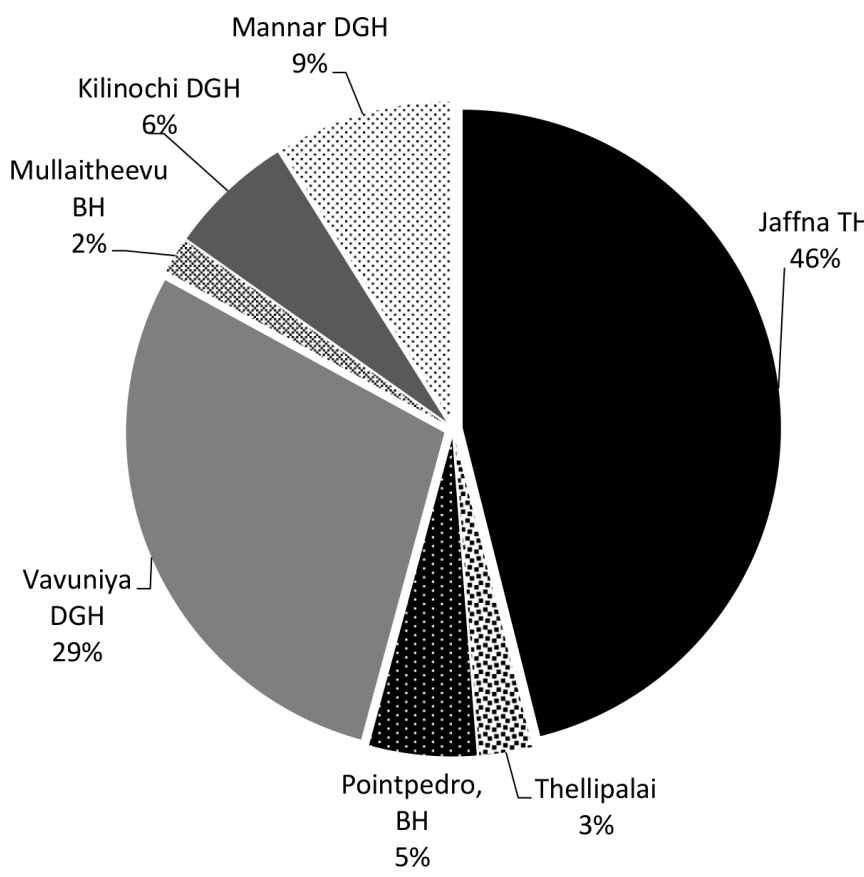

Figure 1 Percentage of road traffic collision patients received per hospital. $\mathrm{BH}$, base hospital; $\mathrm{DGH}$, district general hospital; $\mathrm{TH}$, teaching hospital.

\section{Patient and public involvement}

Patients and patient advisors were not involved in the creation or conduct of our study.

\section{FINDINGS OF THE TRAUMA REGISTRY}

During the first month of data collection, 280 patients were abstracted. Hospital book registers revealed 505 road traffic injuries admitted to the study hospitals during that month; thus, only $55.4 \%$ of patients were identified. Additional training, monitoring and auditing raised this number to $66 \%$ of the estimated patients injured in the region.

\section{Demographics}

Between 1 June and 30 September 2017, 1708 people were involved in road traffic crashes; 68 died. The Jaffna Teaching Hospital received $46 \%$ of the injured patients (figure 1). The largest group of patients was between the ages of 21 and 30 years old $(n=516 ; 30.2 \%)$. Men were more likely to be involved in a crash, $62 \%$ of the injured. Nearly half of all victims (48\%) who reported their role in the family were the main providers, with another $20 \%$ a partial contributor. Other demographic variables are listed in table 1.

\section{Types of vehicles}

Of the 1708 patients involved in the crashes, 729 (71.3\%) were riding a motorcycle, either the driver $(71 \%)$ or the passenger (29\%) (figure 2). The mode of transportation was not reported in 686 of the victims. Pedestrians were the second most frequently injured group with 76 (7.4\%) injured patients (figure 2). Most collisions involved an impact with another motorcycle (34\%), fixed objects 
Table 1 Demographics of road traffic collision victims

Patients (n) Percentage

\begin{tabular}{|c|c|c|}
\hline \multicolumn{3}{|l|}{ Sex } \\
\hline Male & 1056 & 62 \\
\hline Female & 652 & 38 \\
\hline \multicolumn{3}{|l|}{ Age } \\
\hline$<20$ & 113 & 6.60 \\
\hline $21-30$ & 516 & 30.20 \\
\hline $31-40$ & 386 & 22.60 \\
\hline $41-50$ & 393 & 23.00 \\
\hline $51-60$ & 126 & 7.38 \\
\hline $61-70$ & 109 & 6.40 \\
\hline$>70$ & 65 & 3.80 \\
\hline
\end{tabular}

Education

\begin{tabular}{|c|c|c|}
\hline$<5$ th grade & 197 & 17 \\
\hline A/L (approximately 13 years) & 675 & 59 \\
\hline Undergraduate & 212 & 18 \\
\hline Postgraduate & 63 & 6 \\
\hline Unknown & 561 & \\
\hline \multicolumn{3}{|l|}{ Family economic status } \\
\hline$<20000 /$ month & 387 & 22.90 \\
\hline $20000-40$ 000/month & 774 & 45.80 \\
\hline$>40000 /$ month & 530 & 31.30 \\
\hline Unknown & 17 & \\
\hline \multicolumn{3}{|l|}{ Victim's role in family } \\
\hline Not contributing & 512 & 32 \\
\hline Partial contribution & 309 & 20 \\
\hline Breadwinner & 767 & 48 \\
\hline Unknown & 120 & \\
\hline \multicolumn{3}{|l|}{ Road traffic crash history } \\
\hline No previous road traffic crash & 347 & \\
\hline Previous road traffic crash & 119 & \\
\hline
\end{tabular}

A/L, advanced level education.

$(14 \%)$ or uncontrolled livestock $(12 \%)$; no data were available for 790 patients. The greatest percentage of crashes $(52 \%)$ occurred on highways, $328(64.1 \%)$ occurring between 40 and $80 \mathrm{~km} /$ hour $(25-50 \mathrm{mph})$. Poor road surfaces, poor lighting and alcohol were not major contributing factors (table 2).

\section{Prehospital care}

Three-wheeled vehicles were the dominant mode of transportation to treatment centres, transporting 311 of 591 victims in whom the transport mode was reported; 89 patients travelled by ambulance. Transportation time to the hospital of 1-2 hours was common, reported in 408 patients $(52 \%)$. For $24 \%$ of the injured patients, it took more than 2 hours to reach a treatment centre. Very few patients $(\mathrm{n}=164 / 657,25 \%)$ received any first aid prior to arriving at the hospital.

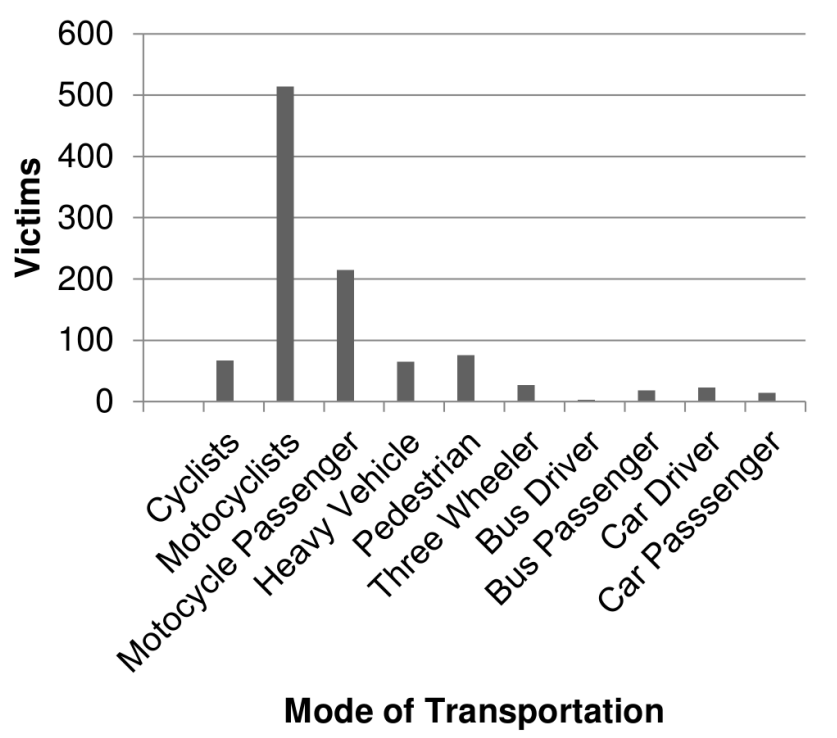

Figure 2 Type of transportation at time of collision.

\section{Injuries}

The most prevalent injuries were extremity injuries ( $\mathrm{n}=810$; 313 upper extremities, 497 lower extremities); chest $(n=379)$ and head $(n=315)$ injuries were also common (table 3). Fracture stabilisation was the most frequent intervention, performed 417 (30\%) times,

Table 2 Factors contributing to road traffic collision

Patients (n) Percentage

\begin{tabular}{lrc}
\hline Place of injury & & \\
Side roads & 294 & 37 \\
Path or field & 87 & 11 \\
Highway & 412 & 52 \\
$\quad$ Unknown & 915 & \\
Approximate speed (km/hour) & & \\
$<40$ & 91 & 17.8 \\
$40-80$ & 328 & 64.1 \\
$80-100$ & 64 & 12.5 \\
$>100$ & 29 & 5.7 \\
Unknown & 1196 &
\end{tabular}

Road surface condition

\begin{tabular}{lrr} 
Poor & 109 & 21 \\
Good & 417 & 79 \\
Unknown & 1182 & \\
Light & & \\
Poor & 95 & 12 \\
Adequate & 703 & 88 \\
$\quad$ Unknown & 910 & \\
Alcohol consumption & & \\
Consumed & 83 & 5 \\
$\quad$ Not consumed & 1625 & 95 \\
\hline
\end{tabular}




\begin{tabular}{|c|c|c|}
\hline & Patients (n) & Percentage \\
\hline \multicolumn{3}{|l|}{ Injury pattern } \\
\hline Head injury & 315 & \\
\hline Facial injuries & 276 & \\
\hline Chest injuries & 379 & \\
\hline Abdominal injuries & 219 & \\
\hline Spine and pelvic injuries & 217 & \\
\hline Limb injuries & 810 & \\
\hline \multicolumn{3}{|l|}{ In-hospital treatment } \\
\hline Oral medications and discharge & 229 & 16.0 \\
\hline Wound cleaning and dressing & 387 & 28.0 \\
\hline Suturing & 219 & 16.0 \\
\hline Fracture stabilisation & 417 & 30.0 \\
\hline Surgery & 134 & 10.0 \\
\hline Unknown & 322 & \\
\hline \multicolumn{3}{|l|}{ Hospital length of stay } \\
\hline$<1$ day & 484 & 35.5 \\
\hline $2-5$ days & 615 & 46.4 \\
\hline $5-7$ days & 109 & 8.2 \\
\hline$>1$ week & 118 & 8.9 \\
\hline \multicolumn{3}{|l|}{ Disability post road traffic accident } \\
\hline No issue with job & 147 & 17.2 \\
\hline Could not work for some period & 603 & 70.6 \\
\hline Could not continue current job & 87 & 10.2 \\
\hline Medically unfit to work & 16 & 1.9 \\
\hline
\end{tabular}

followed by wound care 387 (28\%). Procedure details were unknown for 322 patients. The average length of stay for patients was $2-5$ days (table 3 ). Following their injuries, $87(10.2 \%)$ of patients were unable to return to their previous work and $16(1.9 \%)$ were unable to work at all (table 3 ).

\section{LESSONS LEARNT FROM ESTABLISHING THE TRAUMA REGISTRY \\ Data issues}

While the total number of patients registered was close to the number anticipated, many registry components were incomplete. Only 1040 crashes out of 1708 (61\%) were reported to the police. Network connections were slow and failed frequently. There were technical issues with the software and tablets. Patients sometimes refused to participate in data collection. The medical officers responsible for data collection on inpatients had a heavy workload and were at times unable to complete data. Nursing staff failed to complete patient details for whom they were responsible. Some data were unavailable. Planned home visits and postinjury family dynamics could not be adequately assessed due to lack of social services.

\section{Importance of the registry}

Road traffic morbidity and mortality are a worldwide public health challenge, with an estimated 50 million people each year being injured or disabled in a road traffic crash and $90 \%$ of deaths occurring in LMICs, more than one-third occurring in South-East Asia. ${ }^{3}{ }^{12}$ These road traffic crashes result in $30 \%-86 \%$ of all trauma admissions in LMICs; increasing numbers are anticipated, with an estimated increase of $80 \%$ from traffic injuries expected in LMICs by the year $2020 .^{3}$

Trauma registries provide timely and reliable information on the incident and patient outcomes. Thus, they provide the foundation for an effective trauma system. The WHO Injury Surveillance Guidelines can be used as a foundation for assuring adequate information on injury to accurately guide injury care policy. ${ }^{13}$ The American College of Surgeons Committee on Trauma is also developing an international data bank with a minimum data set. ${ }^{14}$

\section{Barriers to prior implementation}

Prior efforts to establish a trauma registry in Sri Lanka failed due to incomplete data entry, excessive workload, politically controlled processes, and the biggest challenge in an LMIC, funding. ${ }^{15}$ This new registry established a straightforward method to collect reproducible data. The study was endorsed by the Sri Lankan Ministry of Health, and conducted in the northern region, a site plagued by civil war until recently. A recent review of international trauma registries identified factors valuable in assessing the efficacy of such a database. ${ }^{16}$ For the Sri Lankan registry, the use of an electronic mobile app with dedicated and trained data abstractors, external nonprofit funding, multi-institutional participation, patient outcome data, family and socioeconomic issues, data quality control and data analysis at the institutional and provincial level were important.

\section{Current obstacles}

The goal of this project was to provide data to healthcare professionals and policy makers to (1) identify the gaps in the healthcare system; (2) encourage active involvement of healthcare professionals; (3) optimise early injury care at the scene and in the hospital; (4) guide protective gear legislation; (5) regulate the referral system and patient transport; (6) customise injury prevention strategies; (7) collaborate with other system contributors: police, road development authority, legal system, social service, local government and health ministry; (8) policy making and allocation of resources; and (9) to develop a sustainable trauma care system. The issues identified during implementation of this registry are not unique to Sri Lanka. ${ }^{17}$ Work overload of medical officers led to a significant amount of missing data, and the slow tablet speed and poor internet connectivity within the wards led to a $30 \mathrm{~min}$ data entry time for a single patient. 


\section{Economic and societal burden}

Those injured by road traffic crashes are in their prime years of productivity, magnifying the impact on the victims, their families and communities. ${ }^{1}$ The WHO reported in 2015 that road traffic injuries were the leading cause of death between 15 and 29 years of age ${ }^{3}$; in our study, $30.2 \%$ of Sri Lankan road traffic injuries occurred in ages 21-30 years. Men are more frequently injured in road traffic crashes, $67 \%$ in our study. This age/sex distribution is like other countries, problematic because these individuals are often the major provider for the family. Nearly half $(48 \%)$ of all road traffic crash victims in Sri Lanka provided the primary source of income for their families. A study conducted in Bangladesh reported that household income, food consumption and food production declined $70 \%$ when their head of household was involved in a road traffic crash. ${ }^{3}$

South-East Asian countries and other LMICs have a high percentage of 'vulnerable road populations'motorcyclists, both drivers and passengers, bicyclists, and pedestrians. ${ }^{18}$ There are also high numbers of twowheeled and three-wheeled vehicles due to their affordability in less economically advantaged countries. ${ }^{3}{ }^{12}$ Our results, confirming the dominant role of motorcycle crashes $(71.3 \%)$, are depicted in figure 2. South-East Asia and the Western Pacific Region combine to a total of $68 \%$ of the world's motorcycle deaths. ${ }^{1}$ While less prevalent in Sri Lanka, pedestrians are another critical vulnerable population (figure 2). A review of 38 studies found that pedestrian deaths ranged from $41 \%$ to $75 \%$ of all trafficrelated fatalities. ${ }^{3}$ Collisions with free-roaming cattle were responsible for $12 \%$ of crashes, an injury mechanism not previously reported.

\section{Access to care}

The 'golden hour' in trauma, a standard reference in HICs, refers to the transport of an injured patient to a trauma centre within 1 hour from time of injury. ${ }^{19}$ Patients arriving after this time frame have a higher death rate. Data from the Sri Lankan Trauma Registry demonstrated that only $52 \%$ of patients arrived at the hospital within 2 hours after injury, with very few of these patients receiving any prehospital care. A study in India confirmed $80 \%$ of trauma patients were unable to reach medical care within 1 hour of trauma. ${ }^{20}$ In a study by Sharma, ${ }^{12}$ mortality among people with critical but potentially survivable injuries was sixfold lower in HICs $(6 \%)$ than in low-income countries (36\%). Prehospital trauma care systems are generally undeveloped in LMICs, so community leaders, police officers or taxi drivers may be the first responders. ${ }^{11221}$ The predominant mode of transport to the hospital in our study was three-wheeled cycles.

\section{Future plans}

Anticipated modifications of the registry include expansion of the CeCER, software and hardware upgrades, avatar injury mapping, offline functionality and GPS (global positioning system) injury location. An SOS app for injury response by ambulance services has been developed. The number of data collectors for each district is being increased, coordination with social services improved, preservation of patient confidentiality augmented, and safeguards for the safe use of trauma registry data and reports developed. Incorporation of death data for the region would also be important. ${ }^{22}$ Negotiations are under way to enable national collaboration and development of international partnerships.

From the data obtained in this study, plans have been developed to conduct trauma first aid workshops and training programmes for school children, sports clubs and youths. The data will be used to conduct public and media awareness programmes of the importance of injury in Sri Lanka. Other proposed interventions include reflective paint for stray cattle, a reflective jacket for night riders, locating ambulances close to areas with a high incidence of injury, GPS for ambulances to find injury scenes and mobilise quickly, prehospital paramedic training, first aid training for all three-wheeled drivers and provision of first aid boxes near high injury sites.

Quality improvement in trauma systems must be continually assessed through the registry to pursue effective measures and discontinue ones that do not improve outcomes. ${ }^{15}$ The WHO recommends implementation of morbidity and mortality conferences and preventable death reviews. ${ }^{23}$ Countries must invest in the elements of a trauma system in order to see improvements in care of the injured. However, each country has unique issues with trauma system development, and these must be acknowledged if success is to be achieved. ${ }^{13142425}$

\section{CONCLUSION}

Studies in LMICs have shown reduced mortality and medical errors after implementing the elements of a trauma system-a trauma registry, trauma programmes, peer review and quality improvement committees (Pakistan, Thailand-mock success). Sri Lanka has developed a National Policy and Strategic Framework for Injury Prevention and Management. ${ }^{26}$ Implementation of the recommendations requires national investment in a trauma system with all the elements needed to be most effective. This trauma registry and the leadership exhibited in northern Sri Lanka are an excellent start to this process.

Contributors TG contributed to data collection, data analysis and interpretation, and critical edits. AMB contributed to data interpretation, article drafting and critical revisions. $\mathrm{CH}$ contributed to article drafting and critical revisions. MM contributed to design, data analysis and interpretation, article drafting, and critical revisions.

Funding Grant support was received from The Asia Foundation, San Francisco Headquarters (San Francisco, California) and Arogya World (Naperville, Illinois).

Competing interests None declared.

Patient consent for publication Not required.

Provenance and peer review Not commissioned; externally peer reviewed.

Data availability statement All data relevant to the study are included in the article or uploaded as supplementary information. 
Open access This is an open access article distributed in accordance with the Creative Commons Attribution Non Commercial (CC BY-NC 4.0) license, which permits others to distribute, remix, adapt, build upon this work non-commercially, and license their derivative works on different terms, provided the original work is properly cited, appropriate credit is given, any changes made indicated, and the use is non-commercial. See: http://creativecommons.org/licenses/by-nc/4.0/.

ORCID iD

Mary McCarthy http://orcid.org/0000-0002-9425-0152

\section{REFERENCES}

1 Toroyan T, laych K, Peden M, et al. World Health organization global status report on road safety, 2015. Available: http://www.who.int/ violence_injury_prevention/road_safety_status/2015/en/ [Accessed 7 Nov 2018].

2 GBD 2016 Causes of Death Collaborators. Global, regional, and national age-sex specific mortality for 264 causes of death, 19802016: a systematic analysis for the global burden of disease study 2016. Lancet 2017;390:1151-210.

3 Peden M, Scurfield R, Sleet D, eds. World report on road traffic injury prevention, 2004. http://www.who.int/violence_injury_ prevention/publications/road traffic/world report/en/

4 United Nations Road Safety Collaboration. Decade of action for road safety 2011-2020, 2010. Available: http://www.who.int/roadsafety/ decade_of_action/en/ [Accessed 12 Nov 2018].

5 Mock C, Joshipura M, Arreola-Risa C, et al. An estimate of the number of lives that could be saved through improvements in trauma care globally. World J Surg 2012;36:959-63.

6 Mullins RJ, Mann NC. Population-based research assessing the effectiveness of trauma systems. J Trauma 1999;47:S59-66.

7 Moore L, Clark DE. The value of trauma registries. Injury 2008;39:686-95.

8 Mock CN, Adzotor KE, Conklin E, et al. Trauma outcomes in the rural developing world: comparison with an urban level I trauma center. $J$ Trauma 1993;35:518-23.

9 Celso B, Tepas J, Langland-Orban B, et al. A systematic review and meta-analysis comparing outcome of severely injured patients treated in trauma centers following the establishment of trauma systems. J Trauma 2006;60:371-8.

10 Mock C, Lormand JD, Goosen J, et al. Guidelines for essential trauma care. World Health Organization, Geneva, (2004). Available: http://whqlibdoc.who.int/publications/2004/9241546409.pdf [Accessed 12 Nov 2018].

11 Japan International Cooperation Agency, Ministry of Healthcare and Nutrition Sri Lanka. The development study on evidence-based management for the health system in Sri Lanka: final report. Main report, Chapter 5 Trauma. In: Roadmap for implementation. 1, 2007. http://open_jicareport.jica.go.jp/pdf/11864238_07.pdf

12 Sharma BR. Road traffic injuries: a major global public health crisis. Public Health 2008;122:1399-406.

13 Holder Y, Peden M, Krug E, eds. Injury surveillance guidelines. Geneva: World Health Organization, 2004. http://apps.who.int/iris/ bitstream/handle/10665/42451/9241591331.pdf?sequence=1\& isAllowed=y

14 American College of Surgeons Committee on Trauma. International data registry personal communication (Maria Jimenez, chair international injury care Committee); 2018.

15 St-Louis E, Paradis T, Landry T, et al. Factors contributing to successful trauma registry implementation in low- and middleincome countries: a systematic review. Injury 2018;49:2100-10.

16 Haider AH, Hashmi ZG, Gupta S, et al. Benchmarking of trauma care worldwide: the potential value of an international trauma data bank (ITDB). World J Surg 2014;38:1882-91.

17 Schultz CR, Ford HR, Cassidy LD, et al. Development of a hospitalbased trauma registry in Haiti: an approach for improving injury surveillance in developing and resource-poor settings. J Trauma 2007;63:1143-54.

18 Ameratunga S, Hijar M, Norton R. Road-Traffic injuries: confronting disparities to address a global-health problem. Lancet 2006;367:1533-40.

19 Anand LK, Singh M, Kapoor D. Prehospital trauma care services in developing countries. APIC 2013;17:65-70.

20 Aekka A, Abraham R, Hollis M, et al. Prehospital trauma care education for first responders in India. J Surg Res 2015;197:331-8.

21 Fernando DM, Tennakoon SU, Samaranayake AN, et al. Characteristics of road traffic accident casualties admitted to a tertiary care hospital in Sri Lanka. Forensic Sci Med Pathol 2017;13:44-51.

22 World Health Organization. Emergency and trauma care model trauma system policy, 2004. Available: http://www.who.int/ emergencycare/trauma/essential-care/model/en/ [Accessed 9 Nov 2018].

23 Callese TE, Richards CT, Shaw P, et al. Trauma system development in low- and middle-income countries: a review. J Surg Res 2015;193:300-7.

24 Reynolds TA, Stewart B, Drewett I, et al. The impact of trauma care systems in low- and middle-income countries. Annu Rev Public Health 2017;38:1:507-32.

25 Ministry of Health, Nutrition and Indigenous Medicine. Accident and emergency care policy of Sri Lanka, 2016. Available: http://www. health.gov.lk/moh final/english/public/elfinder/files/publications/ 2017/A-EPolicy2016.pdf [Accessed 9 Nov 2018].

26 Mock C, Juillard C, Brundage S, et al. Guidelines for trauma quality improvement programmes. World Health organization, Geneva, 2009. Available: http://whqlibdoc.who.int/publications/2009/ 9789241597746 eng.pdf [Accessed 6 Dec 2018]. 